\title{
Janelas da cultura local: abrindo oportunidades para inclusão digital de comunidades
}

Isa Maria Freire

Doutora em ciência da informação e professora/pesquisadora da pósgradução em ciência da informação, convênio MCT/Ibict - UFF

E-mail: isa@ibict.br

\section{Resumo}

Relata os resultados parciais da pesquisa Janelas da Cultura Local: Quissamã, RJ, em desenvolvimento pelo Grupo de Pesquisa Informação e Inclusão Social do Ibict, com apoio do Conselho Nacional de Desenvolvimento Científico e

Tecnológico. Registra e oferece à discussão a abordagem teórica e metodológica aplicada ao projeto e, ao mesmo tempo, divulga uma informação sobre a responsabilidade social da ciência da informação, no Brasil. O projeto é implementado em parceria com a Secretaria Municipal de Educação e Cultura de Quissamã, RJ, e tem como campo de pesquisa a Escola Municipal Maria Ilka, no bairro Santa Catarina. Além do relatório científico, que incluirá sugestão de uma metodologia para inclusão digital de comunidades, espera-se como resultado a aquisição de competências em informação pelos participantes locais, e especialmente, contribuir para promover o resgate e o registro da memória cultural do dessa comunidade.

\section{Palavras-chave}

Inclusão digital. Identidade cultural. Gestão da Informação. Responsabilidade social. Ciência da Informação.

\section{Local cultural windows: open doors to digital inclusion of communities}

\begin{abstract}
Research report on the partial results of the project Local Culture Windows: Quissamã, RJ. that is being carried on by Ibict's Research Group on Information and Social Inclusion, sponsored by he National Council for Scientific and Technological Development. It details and discusses the theoretical and methodological approaches used and, at the same time, stresses the social responsability of Information Science in Brazil. The project is being developed jointly with the Municipal Secretariat of Education of Quissamã. It has as its field of research the Municipal School Maria Ilka, in the district/neighbohood of Santa Catarina. Besides the scientific report, that encompasses a proposal of a methodology for digital inclusion of communities, it is also expected as a result the development of competencies in information by the local partners. It is also particularly expected that the project contributes to promote the recovery and to the recording/ registration of thr cultural memory of the neighborhood of Santa Catarina.
\end{abstract}

\section{Keywords}

Digital inclusion. Cultural identity. Information management. Social responsibility. Information science.

\author{
INTRODUÇÃO
}

presente trabalho foi produzido no âmbito das discussões do projeto de pesquisa Janelas da Cultura Local: Quissamã, RJ, em desenvolvimento pelo Grupo de Pesquisa Informação e Inclusão Social do Instituto Brasileiro de Informação em Ciência e Tecnologia (Ibict) com apoio do Conselho Nacional de Desenvolvimento Científico e Tecnológico (CNPq). ${ }^{*}$

Nosso propósito é registrar a abordagem teórica e metodológica aplicada ao projeto e, ao mesmo tempo, divulgar uma informação que julgamos ser de interesse para o campo da ciência da informação, no Brasil. ${ }^{* *} \mathrm{Na}$ pesquisa, utilizamos uma rede conceitual (WERSIG, 1993; FREIRE, 2001) tecida a partir de um conceito de informação (BELKIN; ROBERTSON, 1976; ARAÚJO, 1994; BARRETO, 1994; 1996), considerando os aspectos funcionais dos novos produtos de informação nos espaços globais (GONZÁLEZ DE GÓMEZ, 1997; 2004). Nossas premissas são a informação como força de transformação (ARAÚJO, 1994; ARAÚJO; FREIRE, 1999), a responsabilidade social da ciência da informação (WERSIG, NEVELING, 1975; FREIRE, 2001) e sua relação intrínseca com a tecnologia da informação (SARECEVIC, 1995; PINHEIRO, 1997; FREIRE, 2004), que se manifestam no desenvolvimento de competências para produção e comunicação de informação em uma comunidade, contribuindo para dotar os participantes de elementos de mediação entre a cultura local e a cultura global.

A abordagem metodológica se pauta no caráter interativo das tecnologias digitais de informação e comunicação e na participação da comunidade no processo de construção de interfaces de organização e comunicação

\footnotetext{
* CNPq - Processos n.304820/2004-0/Mod. PQ e n.401830/2004-7/Mod. APQ. Participam como pesquisadores convidados os doutores Gustavo Henrique de Araújo Freire e Vânia Maria Rodrigues Hermes de Araújo; como pesquisadores colaboradores os mestres Bruno Macedo Nathansohn, Carmelita do Espírito Santo, Márcio Gonçalves e Paula Martinez Mello. Participam, também, os especialistas Cristina Gáudio Teixeira e Ricardo Siqueira Neves. O presente texto é especialmente tributário das contribuições dos pesquisadores Gustavo Henrique de Araujo Freire e Carmelita do Espírito Santo.

** Reflexões sobre o tema da pesquisa foram comunicadas em Freire (2004룰 2005; 2006).
} 
da informação cultural local. Nesse sentido, adotaremos os modelos da Pesquisa-Participante, que permite incluir a comunidade local na construção de um produto de informação, como demonstrado por Freire (1998) e Espírito Santo (2003), e da Pesquisa-Ação de Thiollent (1997; 2000), que possibilita a discussão dos procedimentos metodológicos por todos os participantes da pesquisa, favorecendo a correção de rumos e sua adequação às condições locais.

O projeto está sendo implementado em parceria com a Secretaria Municipal de Educação de Quissamã, RJ, tendo como campo de pesquisa a Escola Municipal Maria Ilka, localizada no bairro Santa Catarina.

\section{ENTRE O GLOBAL E O LOCAL}

Nossa premissa é que a informação sempre foi importante no desenvolvimento sociocultural da humanidade, mas ganha nova relevância na sociedade contemporânea, traduzindo-se em números expressivos de produtos e serviços ligados à sua produção e difusão. Mas não se pode negar que o fenômeno da informação foi se tornando mais presente em nossas vidas, e sua área de ação e atuação foi crescendo cada vez mais, até sua identificação com a sociedade contemporânea, qualificada como "sociedade da informação".

Na verdade, o que caracteriza a atual revolução promovida pelas novas tecnologias de informação e comunicação não é a sua centralidade na informação e no conhecimento, mas a transformação destes em forças produtivas. Nesse sentido, já em 1975, Wersig e Nevelling falavam da "nova relevância de um fenômeno antigo". Segundo os autores:

Problemas informacionais existem há longo tempo, sempre estiveram mais ou menos presentes, mas sua importância real ou percebida mudou e essa mudança foi responsável pelo surgimento da ciência da informação, e não apenas dela (WERSIG; NEVELING, 1975 p.127)

Nesse contexto, um dos objetivos da ciência da informação seria o de contribuir para a informação se tornar, cada vez mais, um elemento de inclusão social, oferecendo oportunidades de desenvolvimento para pessoas, grupos e nações. Dessa forma, haveria uma "responsabilidade social" como fundamento para este campo científico, definindo sua atuação na sociedade." Pois, quando cientistas e profissionais da informação organizam textos ou documentos para atender à necessidade de determinado setor da sociedade, acreditam que essas informações serão úteis para seus usuários potenciais e que, delas, resultarão benefícios para a sociedade.

Nas palavras de Freire, "é no espaço social, político e econômico que ocorre o processo da produção e circulação da informação" (FREIRE, 1998, p.103). Na cadeia de comunicação, há uma fonte geradora [emissor] de informação [um texto e sua estrutura], canais de transmissão [mecanismos] e um usuário [receptor]. Relacionando emissor e receptor, existe a intenção [propósito] de atribuir determinado significado à mensagem transmitida, para que esta possa resultar em ação. Nessa perspectiva, a informação teria o "propósito" de alterar a estrutura cognitiva do receptor, como assinalam Belkin e Robertson (1976), tornando-se conhecimento na medida de sua assimilação pelos indivíduos, como acentua Barreto (1996).

É nesse quadro de referência que Barreto vem a definir informação como "estruturas significantes com a competência de gerar conhecimento no indivíduo, em seu grupo, ou na sociedade" (BARRETO, 1996, p.407). Essas estruturas são organizadas em estoques de informação, os quais necessitam de uma ação de comunicação consentida, na medida em que apenas reúnem, selecionam, codificam, reduzem e classificam informação que pode ou não se transformar em conhecimento. Por sua vez, os estoques são armazenados em agregados de informação, tais como bibliotecas, bases de dados, sites da internet, bem como em linguagens documentárias, programas de computação e comunicação de dados e outros mecanismos que possibilitam o processamento, a estocagem, a distribuição e a comunicação da informação. Em outras palavras, tudo que possa intermediar o encontro da informação [estruturas significantes] com o indivíduo [usuário], concorrendo para transformar sua estrutura cognitiva e produzir conhecimento proveitoso para si mesmo e para o ambiente onde vive.

\section{Papel da Internet na sociedade da informação}

O impacto causado pelas tecnologias digitais de informação e comunicação na sociedade contemporânea propiciou o desenvolvimento de um sistema planetário de comunicação que permite a conexão direta entre mais de 50 milhões de indivíduos, alterando as percepções tradicionais de tempo e de espaço, ao mesmo tempo que favorece o início de uma nova dimensão de cidadania.

${ }^{1}$ Conforme Wersig e Nevelling (1975) citados por Freire (2001). 
É nesse sentido que González de Gómez (1999) argumenta que há necessidade de redefinição dos espaços de informação na "sociedade em rede" (CASTELLS, 1999). Segundo a autora, espaços de informação são dispositivos de informação que não só permitem a vinculação comunicacional, cognitiva e fatual de problemas e projetos singulares e locais, mas também podem providenciar sua vinculação a esferas abstratas, distantes e extensas, de modo a favorecer a generalização social dos projetos e problemas. Nessa perspectiva, problemas e projetos locais e globais se articulam, concorrendo para a redefinição das agendas e dos conteúdos temáticos das políticas públicas, à luz da opinião dos atores envolvidos. Assim, o escopo e abrangência dos espaços de informação dependeriam de sua ancoragem tanto nas esferas locais de produção e comunicação, quanto na disponibilidade de acesso às fontes globais de informação.

É nesse contexto que se insere o papel da Internet como principal espaço de informação na sociedade contemporânea. A Internet, enquanto ampla rede de comunicação constituída a partir de locais de informação, seja de armazenamento ou de distribuição, criou um novo espaço de circulação da informação: ciberespaço. Este termo foi empregado pelo novelista William Gibson, em meados da década de 1980, para descrever um meio ambiente eletrônico no qual os dados e programas de acesso à informação poderiam ser manipulados. Lévy nos esclarece que

o ciberespaço designa ali o universo das redes digitais, como lugar de encontros e de aventuras ... nova fronteira econômica e cultural. [Atualmente,] designa menos os novos suportes de informação do que os modos originais de criação, de navegação no conhecimento e de relação social, por ele propiciados. (LÉVY, 1999, p.104)

Configura-se, portanto, um espaço de informação que, antes de designar espaços físicos, remete a esferas relacionais e simbólicas de sociabilidade, de comunicação e de saber, como ressalta González de Gómez: nesses espaços, "as informações ... são, ao mesmo tempo, nós das redes que entrelaçam os mais diversos fluxos de informação" (GONZÁLEZ DE GÓMEZ, 1999, p.193). Assim, enquanto importante espaço de informação da atualidade, a Internet converte-se em um dispositivo importante para a formação das estruturas significantes da informação. Neste sentido, pode contribuir para concretização de ações de socialização da informação, necessidade básica em uma sociedade na qual o acesso ao conhecimento disponível nos estoques de estruturas significantes [informação] tornou-se fator básico para o desenvolvimento individual e coletivo.

\section{A identidade cultural no processo de globalização}

Amparada nas tecnologias digitais de informação e comunicação, a globalização atravessa as fronteiras nacionais, integrando e conectando comunidades e organizações em novas combinações de espaço-tempo. A comunicação mediada por computadores gera grande diversidade de comunidades virtuais interligadas em rede, caracterizando a metáfora da "aldeia global", conforme assinala Ianni (1995):

A comunidade mundial concretizada com as realizações e as possibilidades de comunicação, informação e fabulação abertas pela eletrônica. [ $\mathrm{Na}$ aldeia global] Províncias, regiões e nações, bem como cultura e civilizações, são atravessadas e articuladas pelos sistemas de informação e comunicação (IANNI, 1995, p.228)

No conceito de "aldeia global", pode-se visualizar a idéia de homogeneização cultural, com a vida social mediada pelo mercado global de estilos, valores, costumes etc. Nesse espaço social, ocorre a difusão de padrões culturais globais que acarretam alienação dos valores e das culturas locais, pois

Enquanto processo de desenvolvimento de complexas interconexões entre sociedades, culturas, instituições e indivíduos, a globalização estimula e favorece a remoção de nossos relacionamentos e de nossas referências de vida de contextos locais para contextos transnacionais (MIRANDA, 2000, p. 81).

Esse problema tornou-se alvo de constante preocupação para governos e sociedades do mundo inteiro, pois a noção de homogeneidade cultural envolve a idéia de perda ou enfraquecimento das identidades culturais locais. Por isso, têm sido adotadas várias medidas para preservar e manter a identidade cultural de cada local, em um mundo cada vez mais globalizado. Para tanto, as tecnologias de informação e comunicação representam papel relevante. Aqui no Brasil, pode-se evidenciar essa preocupação mediante ações formuladas para preservar a identidade cultural do país, como as descritas no Livro Verde da Sociedade da Informação no Brasil (BRASIL, 2000).

De acordo com a literatura, vários e variados conceitos sobre identidade cultural já foram formulados, o que reflete a complexidade do tema nas mais diversas abordagens: Hall (1998), Maicas (1995), Castells (1999), 
Mendonça (2000). Dentre os conceitos observados, citamos Hall, que a define como "aqueles aspectos de nossas identidades que surgem [da sensação de] pertencimento a culturas étnicas, raciais, lingüísticas e, acima de tudo, nacionais" (HALL, 1998, p.8). E Castells, que a entende como "um processo pelo qual um ator social se reconhece e constrói significados com base em determinado atributo cultural ou conjunto de atributos, a ponto de excluir uma referência mais ampla" (CASTELLS, 1999, p.39). Ou, ainda, Catelan (2005), que designa de identidade cultural como o conjunto de hábitos, costumes, ideais, padrões de comportamento, criações artísticas, literárias e folclóricas que formam a personalidade histórica de um povo.

Em Espírito Santo (2003), encontramos a concepção de Maicas (1995), segundo a qual a identidade cultural também pode ser definida conforme a sua contextualização. Em uma visão objetiva, a identidade cultural estaria integrada à idéia de costumes, hábitos, tradições, valores, crenças, formas de viver, de pensar e de comportar, assim como a determinado estilo de existência e de presença na própria comunidade. Em uma concepção subjetiva, a identidade cultural significaria o sentimento de pertencer a uma sociedade, na qual cada um poderia ter o sentido de ser um ator de sua própria história. Contudo, já não é possível, em uma sociedade pautada pela velocidade, pela mídia, pelos deslocamentos constantes, colocar a questão da construção das identidades nos mesmos termos "tradicionais" e conservacionistas (MENDONÇA, 2000). Na globalização, essa idéia de identidade unificada e estável está sendo fragmentada, sendo composta não só de uma, mas de várias identidades, algumas vezes contraditórias ou não resolvidas.

É neste ponto que surge a questão do enfraquecimento das identidades culturais no processo de globalização, em decorrência da emergência do espaço virtual. Há um confronto entre as concepções de identidade cultural amparada na noção de território própria dos padrões tradicionais com a noção de ciberespaço, o qual é desterritorializante por natureza. Em outras palavras, o sentido tradicional criado dentro do conceito de estadonação não encontra referencial dentro da teia mundial da rede [www]. Acostumado a pensar e agir dentro de grupos e instituições referenciais, o sujeito navega à deriva sem modelos nacionais a seguir: não há mais fronteiras, seja para protegê-lo, seja para limitá-lo. Nesse sentido, o ciberespaço é, também, um ambiente multicultural, e esse aspecto representa toda uma riqueza de possibilidades para troca de informação e conhecimento. E, se é um espaço que não restringe culturas e assume a diversidade, é preciso conhecer e respeitar o outro como ele é, a partir e além de suas idiossincrasias. $\mathrm{Ou}$, mais ainda, por causa delas, na tentativa de construção de "um laço social, que não seria fundado nem sobre links territoriais, nem sobre relações institucionais, nem sobre as relações de poder, mas sobre a reunião em torno de centros de interesses comuns" (LÉVY, 2000, p.92).

Assim, a cibercultura é a transformação da própria idéia de cultura. Não é apenas uma adaptação ao mundo virtual, mas, antes, a busca por uma nova idéia de compartilhamento. Sem contar com as referências de culturas tradicionais para legitimá-lo diante do outro, o homem digital vê-se na necessidade de interagir a partir do seu "eu" pessoal, construído e alimentado pela coletividade, em contrapartida a um "eu" cultural. Dessa forma, as culturas ocupariam hoje uma região de fronteira, lugar onde transitam não apenas sujeitos em busca do novo e do estranho, mas indivíduos que lutam pela sobrevivência social e cultural em sua relação com o virtual. A estranheza cultural decorrente da perda do território cede lugar à comunicação e ao conhecimento. E, à medida que se configura a necessidade de socialização da informação para todos, cresce a responsabilidade social da ciência da informação, na condição de ciência que tem como função social a organização, processamento e comunicação dessas informações.

É nesse quadro que o projeto Janelas da Cultura Local: Quissamã, RJ se coloca, tanto como contribuição ao estudo dos processos sociais de produção e comunicação da informação, quanto como proposição de ações de inclusão social por meio da transferência de tecnologias intelectuais e digitais para unidades públicas de ensino.

\section{O CAMINHO E A CAMINHADA}

No presente projeto, propomos o desenvolvimento de ações de informação, de forma participativa, com vistas a promover a competência de pessoas da comunidade em tecnologias intelectuais de informação, incluindo a construção de um hipertexto digital sobre a cultura local, que será o eixo motivacional e operatório da pesquisa.

Na visão de Lévy (1994), um hipertexto pode ser considerado com um mundo de significações, no qual atores da comunicação ou elementos de uma mensagem constroem e remodelam universos de sentido. Dessa forma, pode ser utilizado como metáfora para todas as esferas da realidade em que significações estejam em jogo. $\mathrm{O}$ autor caracteriza o hipertexto de acordo com seis princípios: o da metamorfose, com a rede hipertextual em constante construção e renegociação; o da 
heterogeneidade, que permite variados tipos de associações por meio de diferentes suportes informacionais, diferentes conexões e formatos para a comunicação de mensagens. $O$ da multiplicidade e de encaixe de escalas, que permite a organização do hipertexto de um modo fractal*, com cada link, ou nó da conexão, pode revelar-se como sendo composto por toda uma rede. $\mathrm{O}$ da exterioridade do hipertexto: o crescimento, diminuição, composição e recomposição da rede dependerá sempre da adição constante de novos elementos e conexões com outras redes. O da topologia, pois o hipertexto funciona por proximidade, por vizinhança. Neste caso, não há espaço social homogêneo em que possam coexistir forças de ligação e separação para a circulação livre de mensagens, pois todo deslocamento deve utilizar-se da rede hipertextual. Aqui, a rede não está no espaço, ela é o próprio espaço. $\mathrm{O}$ usuário da informação passa a ter a liberdade de escolher seu próprio percurso e, no caso de compartilhar uma rede como a Internet, construir seus próprios estoques de informação - estratégia informacional que adotamos na presente pesquisa.

Para construção do hipertexto sobre a cultura local com a comunidade de Santa Catarina, em Quissamã, optamos por utilizar a metodologia da pesquisa-participante, utilizada de forma inovadora por Freire (1998) e Espírito Santo (2003). O termo "pesquisa-participante" foi criado por pesquisadores norte-americanos e europeus envolvidos com projetos de intercâmbio com países de terceiro mundo, na área de ciências sociais. A pesquisaparticipante combina:

... técnicas de pesquisa, processos de ensinoaprendizagem e programas de ação educativa que ... apontam para [a promoção]:

a) da produção coletiva de conhecimentos, rompendo o monopólio do saber e da informação, permitindo que ambos se transformem em patrimônio dos grupos marginalizados;

b) da análise coletiva na ordenação da informação e no uso que dela se possa fazer;

c) da análise crítica, utilizando a informação ordenada e classificada, a fim de determinar as raízes e as causas dos problemas e as vias de solução para os mesmos; [e o]

\footnotetext{
* Fractal, em matemática, é a figura geométrica com uma estrutura complexa e pormenorizada em qualquer escala. Geralmente, os fractais são auto-similares, isto é, uma pequena seção de um fractal pode ser vista como uma réplica em menor escala de todo o fractal. Pesquisa Google "fractal". Páginas brasileiras. Julho de 2003. Em www.geocities.yahoo.com.br/ciencia2000 br/fractal.html.
}

d) estabelecimento de relações entre problemas individuais e coletivos, funcionais e estruturais, como parte da busca de soluções para os problemas enfrentados (FREIRE,1998, p.16).

O processo envolve contato permanente entre os participantes da pesquisa (pesquisadores e usuários), sendo que o primeiro momento é dedicado ao conhecimento preliminar da realidade, de modo a identificar o que Goldmann (1970) denomina "informação prévia". Dessa ação, resulta a formação de um grupo de trabalho que, no segundo momento, identifica, na comunidade, os "temas geradores" do conteúdo do hipertexto. Os temas levantados e sua pertinência são discutidos pelo grupo, à medida que a interação entre pesquisadores e usuários da informação favorece a reflexão crítica sobre os temas, que se "abrirão" na direção de outros temas. Assim, uma "informação prévia” será gradualmente incorporada ao hipertexto em construção, e o processo trabalha, ao mesmo tempo, a "consciência real" e a "consciência máxima possível" dos participantes da pesquisa (FREIRE, 1998).

Por sua vez, a escolha da pesquisa-ação traduz a tentativa de abordar a comunicação da informação como ação transformadora, no sentido que lhe atribui Araújo (1994), criando espaço para intervenção empírica em uma dada situação. A pesquisa-ação supõe uma participação e uma forma de ação planejada que atinja os vários elementos das atividades humanas - diretamente relacionada à presente proposta, na medida em que viabiliza a ação coletiva pautada pela resolução de problemas e por objetivos de transformação.

\section{Segundo Thiollent, a pesquisa-ação}

consiste essencialmente em acoplar pesquisa e ação em um processo no qual os atores implicados participam, junto com os pesquisadores, para chegarem interativamente a elucidar a realidade em que estão inseridos (THIOLLENT, 1997, p.15).

Nessa perspectiva, entende-se por "ator" qualquer grupo de pessoas dispondo de certa capacidade de ação coletiva consciente em um contexto social delimitado, podendo designar tanto os grupos informantes no meio de uma organização, quanto os grupos formalmente constituídos, e "participação" é encarada como propriedade emergente do processo, e não como a priori. A metodologia requer clara definição de objetivos em termos de pesquisa e de ação, e o processo não existe de forma totalmente padronizada, pois, dependendo da situação social ou do quadro organizacional em que se aplicam os 
procedimentos, a ordenação das etapas, no decorrer da pesquisa, pode variar.

Buscando uma visão sintética, Dubost (1987) examinou várias concepções de pesquisa-ação vinculadas à tradições norte-americanas e européias, formulando sua própria definição como "ação deliberada visando a uma mudança no mundo real, realizada em escala restrita, inserida em um projeto mais geral e submetida a certas disciplinas para obter efeitos de conhecimento e de sentido" (DUBOST, 1987, citado por THIOLLENT, 1997, p.35). Ele descreve, resumidamente, as cinco principais características da pesquisa-ação:

1. Trata-se de uma experiência ... que se inscreve no mundo real, em uma história concreta e não apenas no mundo do pensamento; os atos dos agentes adquirem o caráter de acontecimentos para todos aqueles que estão implicados; deste ponto de vista, cada operação tem um caráter irreversível ....

2. Esta experiência se desencadeia em escala restrita; essa limitação pode ser o resultado do caráter local ou de aplicação de um princípio de amostragem ....

3. Como 'ação deliberada' que visa a uma mudança efetiva dos grupos e zonas consideradas, ela (a pesquisa-ação) define-se pelos objetivos que podem ser fixados quer pelos proponentes do projeto e as instâncias centrais de poder que lhes dão uma posição de autoridade sobre a população considerada, quer pelo conjunto ou subconjunto dos indivíduos e grupos implicados no processo, quer ainda por um processo de negociação entre os diferentes atores implicados.

4. Desde seu início ela é planejada para produzir ensinamentos possíveis de generalização, para guiar ações ulteriores ou evidenciar princípios ou leis; ela tenta dispor de capacidades de antecipação relacionadas com um projeto mais geral que a engloba, situado em outra escala espacial e temporal e cujos aspectos podem ser modificados, posteriormente em função dos resultados.

5. Ela deve aceitar certas disciplinas, regras ou dispositivos, possibilitando a observação, a coleta de informações cujo processamento condiciona a produção de resultados, o controle e a avaliação dos efeitos (DUBOST, 1987, citado por THIOLLENT, 1997, p.35. Grifo nosso)

Tema central da metodologia de pesquisa-ação, a articulação entre pesquisa e ação é concebida por Desroche de modo diferenciado e em função de uma tipologia das formas de participação. Assim, como pesquisa inserida na ação, a pesquisa-ação comportaria três aspectos simultâneos:

a) pesquisa SOBRE os atores sociais, suas ações, transações, interações; seu objetivo é a explicação;

b) pesquisa PARA dotar de uma prática racional as práticas espontâneas; seu objetivo é a aplicação;

c) pesquisa POR, ou melhor, PELA ação, isto é, assumida por seus próprios atores (autodiagnóstico e autoprognóstico) tanto em suas concepções quanto em sua execução e seus acompanhamentos; seu objetivo é a implicação. (DESROCHE, 1990, citado por THIOLLENT, 1997, p.37).

Para Thiollent, a simultaneidade desses três aspectos impede que a pesquisa-ação seja confundida com a "observação participante", que se limita a uma pesquisa SOBRE. Ele lembra que o uso do termo explicação deve incluir o conceito de compreensão, associado às metodologias qualitativas ou interpretativas. Por sua vez, aplicação se relaciona à idéia de transpor conhecimentos gerais de uma teoria para um contexto concreto, pois nem sempre uma teoria dá conta dos problemas da situação em estudo e que melhor pensar a pesquisa como relação entre teoria e prática. ${ }^{*}$ No que diz respeito à implicação, ele distingue duas características principais: a efetividade, ou reciprocidade, do relacionamento entre pesquisadores e atores, e a clareza dos posicionamentos de cada parte envolvida na pesquisa no plano ético.

Embora um projeto de pesquisa-ação não tenha forma totalmente predefinida, considera-se que existem, no mínimo, quatro grandes fases, aplicáveis ao presente projeto, a saber:

- fase exploratória, na qual pesquisadores-autores e membros das organizações parceiras começam a identificar os elementos da situação em estudo, os atores, as capacidades de ação e os tipos de ação possível, no contexto;

- fase da pesquisa em si, na qual a situação é investigada por meio de diversos tipos de instrumentos de coleta de dados, os quais são discutidos, produzidos e progressivamente aplicados pelos participantes da pesquisa;

- fase de ação, que consiste em difundir os resultados da pesquisa, definir objetivos a serem alcançados por meio de ações concretas, apresentar propostas a serem negociadas entre as partes interessadas na continuidade do projeto.

\footnotetext{
"Entendemos a "pesquisa aplicada" de Thiollent como a "pesquisa prática" de Demo (2000), ou ligada à prática de usar o conhecimento científico para fins explícitos de intervenção em uma dada situação.
} 
- fase de avaliação, que tem por objetivos observar, interpretar e redirecionar as ações em relação aos resultados do projeto, assim como resgatar o conhecimento produzido no decorrer do processo.

No início da pesquisa, as fases são seqüenciais, mas, na prática, existe entre as três últimas um tipo de interação ou mesmo de simultaneidade da pesquisa e da ação. Entretanto, as quatro fases estão relacionadas entre si, sendo que a "pesquisa" alimenta a "ação" e vice-versa. No presente projeto, integramos à abordagem de Dubost a visão cooperativa de Desroche (1990), que define a pesquisa-ação como uma pesquisa

...na qual os autores de pesquisa e os atores sociais se encontram reciprocamente implicados: os atores na pesquisa e os autores na ação. No limite, esses dois papéis tendem a identificar-se em uma só instância de operação. (...) na pesquisa-ação os atores deixam de ser simplesmente objeto de observação, de explicação ou de interpretação. Eles tornam-se sujeitos e parte integrante da pesquisa, de sua concepção, de seu desenrolar, de sua redação e de seu acompanhamento (DESROCHE, 1990, citado por THIOLLENT, 1997, p.36)

Desroche denomina os "pesquisadores" de autores da pesquisa, diferenciados dos "atores" pelo trabalho de redação com uso da escrita. No presente projeto, denominamos "pesquisadores-autores" aos responsáveis pela pesquisa em si (quadro teórico, instrumentos metodológicos, resultados acadêmicos) e "pesquisadoresparticipantes" aos professores da Escola Maria Ilka que aderirem ao projeto, bem como alunos da Escola e pessoas da comunidade envolvidas nas ações do projeto.

O projeto Janelas da Cultura Local: Quissamã, RJ está sendo conduzido como uma rede de pesquisa e desenvolvimento de tecnologias intelectuais e digitais, acompanhado de um programa de capacitação e treinamento de pessoas da comunidade no uso de tecnologias intelectuais e digitais. Serão caracterizados o regime de informação* do município de Quissamã e os elementos constitutivos da

\footnotetext{
* González de Gómez (2004) se refere ao "regime de informação" como uma "dimensão estrutural, que produz um ex antes a toda ação de transferência de informação, independente de nossos desejos e competências singulares. (...) Um 'regime de informação' se desdobra [em] um conjunto mais ou menos estável de redes formais e informais nas quais as informações são geradas, organizadas e transferidas de diferentes produtores, por muitos e diversos meios, canais e organizações, a diferentes destinatários ou receptores de informação, sejam estes usuários específicos ou públicos amplos" (GONZÁLEZ DE GÓMEZ, 2004, p.61).
}

identidade cultural local. Como nosso propósito é construir um hipertexto digital de forma participativa com a comunidade, os aspectos da cultura local a serem abordados serão definidos de acordo com decisões tomadas pelos próprios participantes da pesquisa. A programação das atividades deverá acompanhar o planejamento político-pedagógico da escola, de modo a entrelaçar as ações de informação às ações educacionais.

Podemos antecipar que estão sendo utilizados os seguintes procedimentos:

- visitas regulares a Quissamã, RJ, para contatos com os parceiros locais, ampliação das parcerias e realização de atividades na comunidade;

- reuniões regulares para divulgação, programação, acompanhamento e avaliação das atividades no campo da pesquisa;

- planejamento da Gincana Cultural de Quissamã, para coleta de dados sobre as expressões culturais locais da comunidade;

- programação de oficinas científicas e tecnológicas;

- desenho da Janela da Cultura Local pelos professores da Escola Maria Ilka, para desenvolvimento a partir da contribuição dos alunos e pessoas da comunidade, com acompanhamento dos pesquisadores-autores e apoio dos parceiros locais.

Ao longo do projeto, serão realizados seminários de pesquisa-ação para discussão de aspectos teóricos, metodológicos e operacionais da pesquisa, seminários de divulgação científica, para apresentação dos resultados do projeto para outros grupos da comunidade, para a comunidade científica e para a sociedade em geral, e oficinas de competências em informação para os professores participantes da pesquisa.

Nossa expectativa é que este grupo pioneiro possa agir com sua inteligência coletiva para abrir a primeira janela da cultura local no bairro de Santa Catarina. Uma janela através da qual poderemos ver não somente as palmeiras imperiais, que delimitam o município e denotam seu passado histórico, mas, especialmente, um mundo que está além dos horizontes territoriais, muito além do que já vimos e experimentamos, entretanto ao alcance de um toque no mouse.

Artigo submetido em 16/04/2006 e aceito em 13/03/2007. 


\section{REFERÊNCIAS}

ARAÚJO, V. M. R. H. de. Sistemas de recuperação da informação: nova abordagem teórico-conceitual. 1994. Tese (Doutorado em Comunicação e Cultura) - Escola de Comunicação da UFRJ, Rio de Janeiro, 1994.

; FREIRE, I.M. Conhecimento para o desenvolvimento: reflexões para o profissional da informação. Informação $\mathcal{E}$ Sociedade: estudos, v. 9, n. 1, 1999.

BELKIN, N. J.; ROBERTSON, S. E. Information science and the phenomenon of information. Journal of the American Society for Information Science, v. 27, n. 4, p.197-204, July/Aug. 1976.

BARRETO, A. de A. A eficiência técnica e econômica e a viabilidade de produtos e serviços de informação. Ciência da Informação, v. 25, n. 3, 1996.

. A questão da informação. São Paulo em Perspectiva, v. 8,

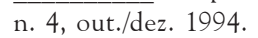

BRANDÃO, C. R. Pesquisar-participar. In: BRANDÃO, C. R. (Org.). Pesquisa participante. 6. ed. São Paulo: Brasiliense, 1986.

BRASIL. Ministério da Ciência e Tecnologia. Sociedade da informação no Brasil: livro verde. Brasília, 2000. Disponível em: <www.mct.gov.br >. Acesso em: 2007.

CASTELLS, M. A sociedade em rede. São Paulo: Paz e Terra, 1999. (A Era da informação: economia, sociedade e cultura).

CATELAN, A. Mundo caipira: história e lendas da música caipira no Brasil. Goiânia: Kelps: Universidade Católica de Goiás, 2005.

DEMO, P. Metodologia do conhecimento científico. São Paulo: Atlas, 2000.

DESROCHE, H. Entreprendre d'apprendre: d'une autobiographie raisonnée aux propjets d'ue recherche-action. Paris: Ed. Ouvrières, 1990.

DUBOST, J. Lintervention psycho-sociologique. Paris: PUF, 1987.

ESPÍRITO SANTO, C. do. "Quissamã somos nós": pesquisa participante para construção de hipertexto sobre identidade cultural. 2003. Dissertação (Mestrado em Ciência da Informação)- Escola de Comunicação, Universidade Federal do Rio de Janeiro, Rio de Janeiro, 2003. Disponível em: < www.isafreire.pro.br > Acesso em: 2007.

. FREIRE, I. M. "Quissamã somos nós!": construção participativa de hipertexto. Ciência da Informação, v. 33, n. 1, 2004. Disponível em: <www.ibict.br/cionline/>. Acesso em: 2007.

FREIRE, G. H. de A. Comunicação da informação em redes virtuais de aprendizagem. 2004. Tese (Doutorado em Ciência da Informação)- Escola de Comunicação, Universidade Federal do Rio de Janeiro, Rio de Janeiro, 2003. Disponível em: < $\underline{w w w . i s a f r e i r e . p r o . b r}>$. Acesso em: 2007.

. A construção de instrumento para comunicação de informação sobre saúde. 1998. Dissertação (Mestrado em Ciência da Informação)Escola de Comunicação, Universidade Federal do Rio de Janeiro, Rio de Janeiro, 1998. Disponível em: < http://ghafreire.sites.uol.com.br>. Acesso em: 2007.

FREIRE, I. M. Acesso à informação e identidade cultural: entre o global e o local. Ciência da Informação, v. 35, n. 2, p. 58-67, maio/ago. 2006.
- A utopia planetária de Pierre Lévy: uma leitura hipertextual d'a inteligência coletiva. Perspectivas em Ciência da Informação, v. 10, n. 2, p. 132-139, jul./dez. 2005.

. O desafio da inclusão digital. Transinformação, v. 16, n. 2, 2004a. Disponível em: http://revistas.puc-campinas.edu.br/transinfo/ include/getdoc.php?id=191\&article $=68$ mode $=$ pdf. Acesso em: 2007 .

- A responsabilidade social da ciência da informação na perspectiva da consciência possível. DataGramaZero, v. 5, n. 1, 2004 b. Disponível em:

$<$ http://www.datagramazero.org.br/fev04/F_I_art.htm >. Acesso em: 2007.

- A responsabilidade social da ciência da informação e/ou $O$ olhar da consciência possível sobre o campo científico. 2001. Tese (Doutorado em Ciência da Informação)- Escola de Comunicação, Universidade Federal do Rio de Janeiro, Rio de Janeiro, 2003. Disponível em: $<$ www.isafreire.pro.br $>$. Acesso em: 2007.

; ARAUjO, V. M. R. H. de. Tecendo a rede de Wersig com os indícios de Ginzburg. DataGramaZero, v. 2, n. 4, 2001. Disponível em: <http://www.datagramazero.org.br/ago01/ F I art.htm $>$. Acesso em: 2007.

; FREIRE, G. H. de A. Navegando a literatura: o hipertexto como instrumento de ensino. Transinformação, v. 10, n. 2, maio/ago. 1998.

GOLDMANN, L. Importância do conceito de consciência possível para a informação. In: O CONCEITO de informação na ciência contemporânea: colóquios filosóficos de Royaumont. Rio de Janeiro: $\mathrm{Paz}$ e Terra, 1970.

GONZÁlEZ DE GÓMEZ, M. N. Novas fronteiras tecnológicas das ações de informação: questões e abordagens. Ciência da Informação, v. 33 , n. 1, 2004.

. Da política de informação ao papel da informação na política contemporânea. Revista Internacional de Estudos Políticos, v.1, n., p.67-93 abr.1999.

A globalização e os novos espaços da informação. Informare, v. 3, n. 1/2, 1997.

HALL, S. A identidade cultural na pós-modernidade. 2. ed. Rio de Janeiro: DP\&A, 1998.

IANNI, O. Teorias da globalização. 4. ed. Rio de Janeiro: Civilização Brasileira, 1995.

LÉVY, P. A inteligência coletiva: por uma antropologia do ciberespaço. 3. ed. São Paulo: Ed. Loyola, 2000.

. Cibercultura. São Paulo: Editora 34, 1999.

- As tecnologias da inteligência: o futuro do pensamento na era da informática. Rio de Janeiro: Ed. 34, 1994.

MAICAS, Manuel Parès. Consideraciones sobre la identidad cultural. In: MELO, José Marques de. Identidades culturais latino-americanas em tempo de comunicação global. São Bernardo do Campo: Instituto Metodista de Ensino Superior: UNESCO, 1995.

MATTELART, A. História da utopia planetária: da cidade profética à sociedade global. Porto Alegre: Ed. Sulina, 2002.

MARTELETO, R. M. Cultura, educação, distribuição social dos bens simbólicos e excedente informacional. Informare, v. 1, n. 2, 1995. 
MENDONÇA, M. L. Identidade, cultura e ação social: idéias e práticas. In: XXIII CONGRESSO BRASILEIRO DE CIÊNCIAS DA COMUNICAÇÃO, 2000. Disponível em: http://www.intercom.org.br/ papers/xxiii-ci/gt12/art-gt12.html. Acesso em setembro de 2002.

MIRANDA, A. A sociedade da informação: globalização, identidade cultural e conteúdos. Ciência da Informação, v. 29, n. 2, p. 78-88, maio/ ago. 2000.

PINHEIRO, L. V. R. A ciência da informação entre sombra e luz: domínio epistemológico e campo interdisciplinar. 1997. Tese (Doutorado em Comunicação e Cultura) - Escola de Comunicação, Universidade Federal do Rio de Janeiro, Rio de Janeiro, 1997.

SARACEVIC, T. Ciência da informação: origem, evolução e relações. Perspectivas em Ciência da Informação, v. 1, n. 1, 1996.
. Interdisciplinary nature of information science. Ciência da Informação, v. 24, n. 1, 1995.

THIOllent, M. Metodologia da pesquisa-ação. 10. ed. São Paulo: Cortez Ed., 2000.

. Pesquisa-ação nas organizações. São Paulo: Atlas, 1997.

WERSIG, G. Information science: the study of postmodern knowledge usage. Information Processing and Management, v. 29, n. 2, 1993.

; NEVELING, U. The phenomena of interest to information science. The Information Scientist, v. 9, n. 4, 1975. 